Проблемами справедливости в здравоохранении сегодня занимается масса теоретиков и практиков: в их числе Н. Дэниелс, М. Нуссбаум, Дж. Ролз, А. Сен и многие другие.

Так, Норман Дэниелс, автор известной работы «Справедливое здравоохранение», пришел к выводу, что принципы справедливости требуют прежде всего исправлять социальные неравенства общества, которые являются главной причиной нездоровья [1]. Кстати, один из докладов ВОЗ (2009) тоже посвящен влиянию социальных факторов на здоровье людей и проблеме социальной несправедливости, которая, как утверждается в нем, «убивает людей в массовых масштабах» [2]. Таким образом, у Н. Дэниелса здоровье людей стало не условием для достижения большей социальной справедливости, а, наоборот, следствием социальных условий.

По нашему мнению, совершенная система здравоохранения и не может быть создана, так как этому препятствует плюрализм ценностей, образов и уровней жизни, идеологические разногласия и т. п. Приход глобального неолиберализма в медицинскую сферу роковым образом сказался на общественном здоровье.

В любом случае, создание более справедливой системы здравоохранения, с нашей точки зрения, возможно только на пути создания смешанных моделей, рационально комбинирующих элементы рынка и государственного обеспечения медицинской помощью. «Чистые» формы организации здравоохранения показали свою несправедливость и нерезультативность. Однако проектирование новых, смешанных моделей, способных эффективно функционировать - видимо, дело новых длительных экспериментов и социальных инноваций.

$$
* * *
$$

1. Daniels N. Just Health. Cambridge University Press, 2007.

2. Ликвидировать разрыв в течение жизни одного поколения. Соблюдение принципа справедливости в здравоохранении путем воздействия на социальные детерминанты здоровья. - ВОЗ / М., 2009.

\title{
Ушаков Е.В. \\ Этика нанотехнологий: новое проблемное поле исследований и обсуждений
}

Российская академия народного хозяйства и государственной службы при Президенте РФ (Северо-западный институт управления) (Россия, Санкт-Петербург)

doi: 10.18411/trnio-09-2021-107

\section{Аннотация}

В статье рассматривается ряд моральных проблем, связанных с продвижением нанотехнологической отрасли. Обсуждаются такие проблемы, как техническая безопасность и контроль риска нанотехнологий, экологическая безопасность, справедливость и доступ к благам, информационная безопасность. Делается вывод о необходимости участия как специалистов, так и широкой общественности для обсуждения этих проблем и введения надлежащих регуляторных мер.

Ключевые слова: этика, нанотехнологии, технологические риски, моральные проблемы технологического развития, инженерно-техническая этика.

\section{Abstract}

The article discusses a number of moral issues associated with the advancement of the nanotechnology industry. Problems such as technical safety and risk control of nanotechnologies, environmental safety, fairness and access to benefits, information security are considered. It is concluded that the participation of specialists and the public is necessary to discuss these problems and introduce appropriate regulatory measures.

Keywords: ethics, nanotechnology, technological risks, moral problems of technological development, engineering ethics. 
Семейство нанотехнологий - это техники деятельности в диапазоне нанометрических масштабов (1 - 100 нм). Как известно, нанотехнологии считаются одним из ведущих, стратегически важных направлений XXI в. Сегодня эта отрасль бурно развивается. В ее развитие индустриальные страны вкладывают гигантские средства. Как ожидается, будущие нанотехнологии дадут возможность создавать молекулярные структуры с принципиально новой организацией (в том числе с особыми, наперед заданными свойствами - химическими, физическими, биологическими) - например, сверхпрочные, сверхчистые, теплоустойчивые, гибкие, биосовместимые и т.п.

Сам термин «нанотехнология» предложил в 1986 г. американский исследователь Э. Дрекслер. В своих работах он выдвинул проект «молекулярной сборки» необходимых микроструктур и микрообъектов как технологическую задачу для будущего. На самом деле разработки в области нанотехнологий представляют собой семейство разнородных исследований - это химический катализ, эксперименты по созданию наномашин, микроэлектроника на молекулярном уровне, нанотехнологическое производство материалов и др.

Серьезные исследования в области нанотехнологии (а также солидные инвестиции в нее) начинаются в конце XX века. В 1999 г. в США был опубликован официальный отчет Совета по национальной науке и технологии с выразительным названием «Нанотехнология: создавая мир атом за атомом» [1]. В 2001 г. правительством США была учреждена так называемая Национальная нанотехнологическая инициатива, имеющая межведомственный характер и призванная координировать и финансировать проводимые исследования в сфере нанотехнологии. Вслед за США многие страны начинают собственные исследования: Япония, Великобритания, Россия и другие. Сегодня нанотехнологические разработки проводятся и в таких развивающихся странах, как Китай, Индия, Бразилия и Иран. Нанотехнологическая наука приобрела международный, глобальный характер.

Разумеется, нанотехнология имеет и огромное военное значение. Так, в США был создан специальный Институт нанотехнологий для военнослужащих (Institute for Soldier Nanotechnologies), который занимается проблемами обеспечения армии различными новейшими нанотехнологическими разработками (например, в области обмундирования, средств защиты, нейроэлектронных чипов для солдат и др.).

Огромное значение имеют также приложения нанотехнологии в здравоохранении. В настоящее время сформировался масштабный проект наномедицины. Американский исследователь Роберт Фрейтас сделал это название популярным благодаря своей одноименной работе (1999-2003), которая была первым крупным обсуждением потенциала приложений нанотехнологической науки в области медицины [2]. Ряд технологий, которых можно отнести к наномедицинским, уже сейчас используется в медицинской практике, другие - находятся в состоянии интенсивной разработки.

Как и любая инновационная отрасль, нанотехнологии создают новые неопределенности и проблемы. В этой связи сегодня активно формируется новая область исследований и дискуссий - нанотехнологическая этика. К основным моральным проблемам нанотехнологического развития можно отнести следующие.

1. Проблема безопасности и контроля риска нанотехнологических средств.

К примеру, несмотря на бурное развитие наномедицины, данные о безопасности новых наномедицинских средств пока очень ограничены. Если наномедицинские средства предназначаются для длительного нахождения и действия в организме (наноматериалы, наночастицы, нанодатчики и др.), то крайне необходимым становится их исследование в долгосрочном периоде. Например, крайне важно знать, каков будет длительный эффект нанолекарств, проникающих в клетки организма.

Следует отметить, что имеющиеся положительные результаты пока проверены лишь в краткосрочном режиме, а также преимущественно на здоровых добровольцах. Стремление ведущих кампаний поскорее создать новые наномедицинские средства вполне понятно, тем 
более что проведение долгосрочных исследований является технически сложным, а также довольно дорогим предприятием.

Однако из соображений безопасности следует тщательно проверять все возможные риски наномедицинских разработок. К сожалению, руководства и регуляторные механизмы по проверке и одобрению наномедицинской продукции (которые учитывали бы ее высоко инновационную природу и недостаточную базу знаний) пока недостаточно развиты.

2. Экологическая безопасность.

Специфическая особенность нанопродукции - это возможность ее влияния на окружающую среду, ведь новые наноматериалы, наночастицы и другие нанообъекты при выделении в среду могут оказаться токсичными для организма человека и экологических систем. Например, они могут нарушить экологическое равновесие или вызвать заболевания (особенно при их накоплении и последующем попадании в организм с водой, воздухом и т.п.).

В свое время тревогу общественности вызвали прогнозы Э. Декслера (1986) о том, что созданные человеком самовоспроизводящиеся микроскопические нанороботы заполнят собой и разрушат окружающую среду: это так называемый сценарий «серой массы» (gray goo). Позже эти прогнозы были подвергнуты суровой критике и неприятию как надуманные и нереалистичные, что заставило самого Дрекслера сожалеть о высказанных им идеях.

Но, независимо от того, будут ли когда-нибудь созданы подобные самовоспроизводящиеся нанороботы, вредное экологическое воздействие может наступить просто от новых нановеществ, поступивших в окружающую среду. Тем более - если это вещества с какими-то уникальными, радикально новыми свойствами. Проблема обеспечения экологической безопасности в связи с развитием нанотехнологий - сегодня из наиболее бурно дискутируемых тем в нанотехнологической этике.

3. Справедливость и доступ к благам.

Отрасль нанотехнологических разработок в существенной мере способна создать новые проявления несправедливости и неравенства. Например, если вернуться к продвигающемуся проекту наномедицины, то эту проблему спрогнозировать уже сегодня. Высокая стоимость разработок в области наномедицины ведет и к высокой стоимости наномедицинских вмешательств на практике. Соответственно, это напрямую повлияет на проблему доступа к новым видам диагностики, мониторинга, лечения и т.п.

Вполне ожидаемо, что наномедицина станет «элитной» помощью, предназначенной только для «избранных». Люди с низким доходом в развитых странах, а также подавляющее большинство людей в экономически бедных странах (а они составляют также большинство населения планеты) едва ли будут иметь доступ к благам наномедицины.

Ясно также, что высокую стоимость на наномедицинскую продукцию будут удерживать основные владельцы интеллектуальной собственности на нее - крупные кампании (прежде всего транснациональные корпорации), в том числе за счет механизмов патентования. Поэтому сегодня говорят о том, что для снижения стоимости нанопродукции, возможно, потребуются какие-то существенные изменения в правовой регуляции наномедицинских разработок.

Таким образом, назревает еще одна сфера глобальной несправедливости: разрыв в использовании нанотехнологических благ между странами, а также (в еще большей степени) - внутри стран. Поэтому необходимо заранее принимать меры для предупреждения такого обострения несправедливости, тем более, что определенные достижения нанотехнологии могли бы способствовать существенному улучшению жизни людей в бедных странах (например, за счет улучшения качества питьевой воды, питания, окружающей среды, производства массовых средств предупреждения и лечения наиболее важных болезней с точки зрения общественного здоровья и др.).

Высокая стоимость нанотехнологических разработок создает и такую проблему, как перераспределение ресурсов, когда значительные финансы уходят на «элитные» области исследований, в то время как остаются нерешенными острейшие общественные проблемы. 
Европейская Комиссия в своей Рекомендации о Кодексе поведения для ответственных исследований в области нанонауки и нанотехнологии (2008) устанавливает необходимость так планировать исследования в области нанотехнологии, чтобы они преследовали максимально положительный результат для нужд широких слоев общества в целом.

4. Информационная безопасность.

Подобно генетике и биотехнологиям, развитие нанотехнологий способно привести к появлению новых массивов информации о людях, - информации, создающей риски для конфиденциальности и приватности. Так, наномедицинские средства диагностики и мониторинга (например, внутрикорпоральные чипы, датчики и т.п.) будут способны производить большое количество информации об индивидах, которая в том числе может передаваться дистанционно, фиксироваться на внешних носителях, поступать в те или иные информационные системы, базы данных. Как она будет использована, и кто будет иметь к ней доступ - все это остается сложным вопросом.

В связи с высоко инновационной природой таких источников информации могут потребоваться совершенно новые технические решения и механизмы по защите конфиденциальности.

Возможно, что многие страхи и тревоги общественности пока преждевременны (если вообще реалистичны). Тем не менее, нанотехнологическая отрасль наномедицина как масштабный меганаучный проект действительно вызывает ряд обоснованных опасений.

Специфическая особенность нанотехнологической программы в ее предельном виде это стремление к тотальному и прямому инструментальному контролю над природой. Следует также иметь в виду, что нанотехнологические разработки могут быть использованы не только во благо человеку, но и с деструктивной целью.

Причем добиться деструктивных эффектов, по-видимому, даже легче. Например, на основе нанотехнологии можно создать новые виды опасных для человека веществ, которые легко распространять и которые способны причинить огромный вред. В этой связи даже высказывают такое крайнее мнение, что нанотехнологию следует полностью запретить уже сейчас, на ранних стадиях ее развития.

В итоге, все более актуальными становятся проблемы эффективного контроля за развитием нанотехнологий. Для этого необходимо междисциплинарное участие специалистов (включая этиков, экологов, юристов, экономистов и др.), а также широкой общественности для того, чтобы снизить общественные тревоги, улучшить взаимное доверие в этой области, а также предотвратить действительные риски нанотехнологии для общественного блага и общественной безопасности.

$$
* * *
$$

1. Nanotechnology: Shaping the World Atom by Atom. Washington, National Science and Technology Council, 1999

2. Freitas R. A. Jr., Nanomedicine, Volume I: Basic Capabilities, Landes Bioscience, Georgetown, 1999; Freitas R. A. Jr., Nanomedicine, Volume IIA: Biocompactibility, Landes Bioscience, Georgetown, 2003. 